\title{
Erratum to: Coronal plane fracture of the femoral condyles: anatomy, injury patterns, and approach to management of the Hoffa fragment
}

Eric A. White • George R. Matcuk • Aaron Schein •

Matt Skalski • Geoffrey S. Marecek •

Deborah M. Forrester • Dakshesh B. Patel

Published online: 22 October 2014

(C) ISS 2014

Erratum to: Skeletal Radiol

DOI 10.1007/s00256-014-2015-2

The original version of this article unfortunately contained error. The name of "Geoffrey S. Marecek" is incorrectly captured and is now corrected in the author group of this article.

The online version of the original article can be found at http://dx.doi.org/ 10.1007/s00256-014-2015-2.

E. A. White $(\bowtie) \cdot$ G. R. Matcuk $\cdot$ A. Schein $\cdot$ M. Skalski $\cdot$

G. S. Marecek $\cdot$ D. M. Forrester $\cdot$ D. B. Patel

Keck Medical Center of USC, 1500 San Pablo, Los Angeles,

CA 90033, USA

e-mail: ericwhiteusc@gmail.com

G. R. Matcuk

e-mail:matcuk@gmail.com

A. Schein

e-mail: ascheinster@gmail.com

M. Skalski

e-mail: docskalski@gmail.com

G. S. Marecek

e-mail: geoffrey.marecek@med.usc.edu

D. M. Forrester

e-mail: forreste@usc.edu

D. B. Patel

e-mail: patel_dakshesh@yahoo.com 